\title{
Adverse Reactions after Tattooing: Review of the Literature and Comparison to Results of a Survey
}

\author{
Sabrina M. Wenzel Ines Rittmann Michael Landthaler Wolfgang Bäumler \\ Department of Dermatology, University of Regensburg Medical Center, Regensburg, Germany
}

\section{Key Words}

Tattoos · Adverse skin reactions · Hazardous substances

\begin{abstract}
The number of tattooed people has substantially increased in the past years. Surveys in different countries reveal this to be up to $24 \%$ of the population. The number of reported adverse reactions after tattooing has also increased including infections, granulomatous and allergic reactions and tumors. However, the case reports do not reflect the frequency of adverse reactions. This review compares the medically documented adverse reactions published in 1991-2011 with the findings of a nation-wide survey that recently revealed the features and health problems associated with tattoos. To compare the data with the survey, the sex of patients was reported and the location and color of tattoos were evaluated. The results show clearly that colored tattoo inks are mainly responsible for adverse skin reactions and that tattoos on the extremities are involved most. Copyright $\odot 2013$ S. Karger AG, Basel
\end{abstract}

\section{Introduction}

Tattooing is an ancient technique and human tattoos have been identified from ancient times, dating back even to the Stone Age [1]. In some cultures, e.g. Polynesian tribes, tattooing was always an im- portant tool for their religion and hierarchy. The meaning of tattoos in the Western world during the past centuries was ambiguous and was consistently associated with low social status.

Nowadays, tattooing has become very popular in many individuals world-wide. The tattoos are black or multicolored and can be found all over the body, even as socalled permanent make-up [2]. There are many tattooed role models like football, pop or movie stars which has led to a broader cultural acceptance of tattoos. Medical complications after tattooing are often seen by physicians, but are generally unknown to the public. Tattooed individuals or people who consider getting a tattoo are often unaware of the possible effects on their health.

Colored tattoo inks often contain azo pigments that are primarily manufactured for other purposes (e.g. the staining of consumer products) with no established history of safe use in humans. In addition, such pigments can be decomposed during light exposure into hazardous aromatic amines and can be disseminated throughout the human body [3]. Many pigments and, consequently, the decomposition products have been found in the lymph nodes [4-10]. Thus, the tattoo inks, impurities and decomposition products get in close contact with the immune system. Although the first regulations regarding tattoo inks have appeared in some countries, hazardous substances can still be detected
[11-13]. Even if there is a declaration of ingredients, contamination by metal particles which may act as possible antigens cannot be excluded (e.g. nickel) $[14,15]$.

Black tattoo inks are frequently neither analyzed nor controlled prior to use. Their manufacturing process is based on soot, and so they contain toxic, mutagenic or carcinogenic compounds such as carbon black and polycyclic aromatic hydrocarbons (PAHs) or phenol [13]. Furthermore, PAHs can absorb UV radiation and generate cytotoxic singlet oxygen, which might affect skin integrity $[13,16]$.

A survey conducted by Huxley and Grogan in 2005 [17] showed that there 'were no significant relationships between healthy behaviors, health value and numbers of tattoos. A significant proportion of tattooed participants had not considered possible health risks, others were often unaware of potentially serious health problems'. People usually assume that there are governmental regulations for tattoo inks as exist for other products, for example, cosmetics. Unfortunately, this is not true. Over time, various adverse reactions occurring in connection with tattoos have been reported in the medical literature, mostly as case reports or small-case series.

These case reports describe the adverse reaction based on medical examination of the respective patients. However, these single reports cannot provide an overview on the frequency of such adverse reactions.

\section{KARGER}

E-Mail karger@karger.com

www.karger.com/drm
(C) 2013 S. Karger AG, Base

$1018-8665 / 13 / 2262-0138 \$ 38.00 / 0$
Wolfgang Bäumler, PhD, Ass. Prof.

Department of Dermatology

University of Regensburg

DE-93042 Regensburg (Germany)

E-Mail baeumler.wolfgang@ klinik.uni-regensburg.de 
We recently conducted a nation-wide survey to ascertain the frequency of health problems that are associated with tattoos [18]. In this survey, tattooed people were asked to report on their health problems. The results, however, are based on predefined questions, which were answered by medical laypersons.

We aimed to compare the findings of medical reports and the results of the survey. When reviewing the medical literature on tattoo-associated health problems, we considered the reports that appeared in PubMed between 1991 and 2011, using the key words 'tattoos', 'tattooing' 'side effects', 'adverse effects', 'adverse events', 'tattoo reaction', 'health problems' and the various diagnoses in combination with 'tattoo'.

\section{Results and Discussion}

For many years, tattooists used inorganic pigments that contained heavy metals such as mercury, chromium or cadmium. Nowadays, the colored tattoo inks mainly consist of azo or polycyclic pigments [19]. These pigments comprise two perfect features for tattooing: they exhibit brilliant colors and are insoluble in aqueous tissue (fig. 1a). The chemistry of black inks, which predominantly contain carbon black, has not changed considerably. Carbon black is a powder that mainly comprises amorphous particles of carbon with diameters of a few tenths of a nanometer (fig. 1b).

Although they are injected into the human body, tattoo inks usually fulfil no pharmaceutical requirements and contain a long list of admixtures and impurities [13]; a first list of detected substances is shown in table 1 . At present, this list is still incomplete and further chemical analysis of the tattoo inks on the market is required. It is already known that the chemistry of colored and black tattoo inks differs; hence these inks may contain different admixtures and impurities $[13,19]$. Colored pigments (azo dyes and polycyclic compounds) show a complex chemical synthesis containing many byproducts, whereas black inks are produced by imperfect combustion of hydrocarbons yielding soot mainly containing PAH. Consequently, the skin might react differently to colored or black ink suspensions.

In our recently published survey, participants reported adverse reactions immediately after tattooing and 4 weeks afterwards. About $6 \%$ of the 3,411 participants
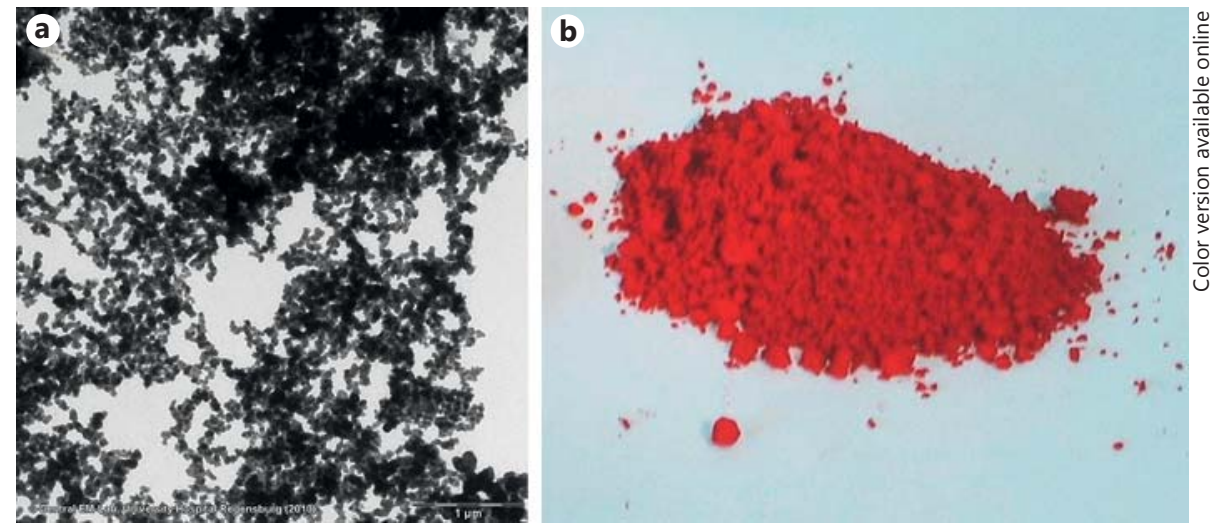

Fig. 1. Electron microscopy shows that tattoo inks (e.g. black inks, a) are usually small particles with diameters in the range of $30-100 \mathrm{~nm}$. To produce a tattoo of about $100 \mathrm{~cm}^{2}$, great amounts of tattoo inks are punctured into skin (carbon black, b).

reported persistent skin problems associated with their tattoos, which were frequently described as itching, intermittent or permanent edema or skin papules. Permanent edema could simply represent the formation of scars or granulomas. These side effects were significantly more frequent in female patients than in males and with colored rather than black tattoos [18].

In this review, we included 122 publications (280 patients) which deal with adverse reactions to decorative tattoos (table 2). We assigned the published cases to the following categories: granulomatous, lichenoid or hypersensitivity allergic reactions (category 1), infections (category 2) and tumors (category 3 , see table 1 ). Some cases that did not fit into these categories are discussed separately. To compare the data with the survey, the sex of patients and location and the color of tattoos, reported in the reviewed case reports were depicted and evaluated in table 3 .

Category 1: Granulomatous, Lichenoid or Hypersensitivity Allergic Reactions

The majority of papers $(n=62)$ describe allergic (often eczematous) and granulomatous reactions inside the tattooed skin area. As mentioned above, tattoo inks may contain various substances which have the potential to induce skin reactions. Once acute inflammatory changes have resolved, delayed reactions can also occur which may vary in time of occurrence from days to several years after tattoo application. $\mathrm{Nu}$ merous clinical reports on these delayed reactions can be found (table 2).
A clear classification of the delayed tattoo reactions according to the clinical appearance and pathological patterns in the reviewed articles proved to be challenging, because the clinical manifestations were often not specific and the histological patterns overlapped. There are several reports of allergic tattoo reactions due to hypersensitivity to a tattoo pigment leading to contact or photoallergic dermatitis.

Various patterns of tattoo reactions were histopathologically described, including granulomatous, lichenoid [20, 21], lymphohistiocytic and pseudolymphomatous [22, 23]. Our classification of the reviewed articles is in line with the diagnoses given in the publications. Medical examination of patients was frequently restricted to a histopathology examination without further test procedures (e.g. allergic testing). Some authors state that of the colored inks, red most frequently caused delayed tattoo reactions [24]. This is usually confirmed by the fact that the emerging tattoo reaction is confined to the red in the tattoo [25]. In the past, red colorants often contained mercury or mercuric sulfide (cinnabar), which obviously acted as antigens.

Histopathological examination of tattoo reactions often showed only nonspecific granulomatous reactions. What the reviewed articles have in common is that granulomatous reactions after tattooing could be subdivided into 2 main categories: sarcoidal granulomas (fig. 2a) and other granulomatous reactions, e.g. foreign body granulomas. It was striking that the majority of cases, which can be assigned to ec- 

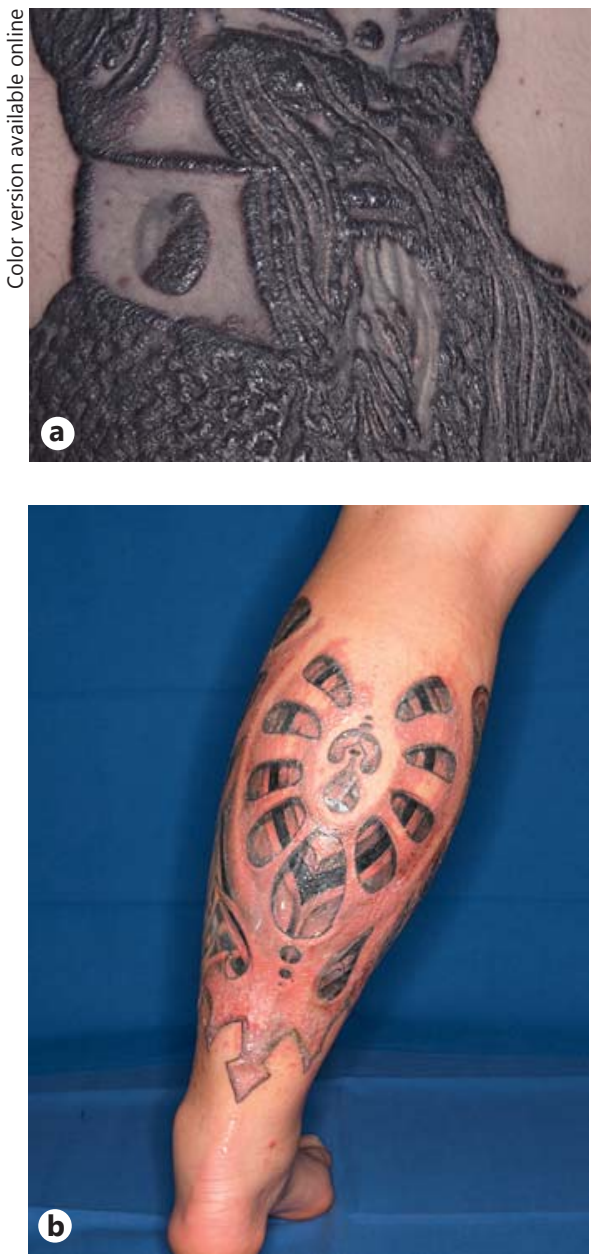

Fig. 2. Examples of adverse tattoo reactions. a A male patient developed sarcoidal granulomas in a tattoo on the upper arm. b A female patient suffered from allergic contact dermatitis with a bacterial superinfection.

zematous, lichenoid or granulomatous reactions were observed in colored tattoos. As mentioned above, this fact might be due to the chemistry of the colored inks used. In view of the various substances in tattoo inks, it remains very difficult to find the trigger for skin reactions after tattooing. Unfortunately, the listing of ingredients is usually not available due to a frequent lack of regulations.

Sarcoidal Granulomas. Sarcoidal granulomas can occur either as an isolated reaction in tattooed skin or they can represent the first 'visible' signs of systemic sarcoidosis. A granulomatous tattoo reaction

Table 1. Substances detected in tattoo inks

\begin{tabular}{lll}
\hline Compounds & References & Comments \\
\hline $\begin{array}{l}\text { Monoazopigment } \\
\text { Disazodiarylide }\end{array}$ & {$[11,19]$} & pigment in color inks \\
Naphthol-AS-pigment & & \\
Quinacridone & & \\
Dioxazine & & \\
$\mathrm{Cu}$-phthalocyanine & & \\
$\mathrm{Cu} / \mathrm{Al}$-phthalocyanine- $\mathrm{Br}_{\mathrm{x}} \mathrm{Cl}_{\mathrm{y}}$ & & \\
\hline
\end{tabular}

\begin{tabular}{lll}
\hline $\begin{array}{l}\text { Mercury } \\
\text { Cadmium }\end{array}$ & {$[62]$} & colored compounds in inks \\
Cobalt & & \\
Chrome & & \\
\hline Carbon black & {$[13,63,64]$} & 'color' of black, brown inks \\
Iron & & \\
\hline Titanium dioxide & {$[19,63]$} & used for whitening of inks \\
Aluminium & & \\
\hline $\begin{array}{l}\text { Naphthol-AS } \\
\text { 2-Methyl-5-nitroaniline }\end{array}$ & {$[65]$} & synthesis educts and \\
2-5-Dichloraniline & & decomposition products of \\
4-Nitro-toluene & azo pigments \\
\hline $\begin{array}{l}\text { PAHs } \\
\text { Phenol }\end{array}$ & {$[13]$} & residue of pyrolysis present \\
\hline $\begin{array}{l}\text { Dibutyl-phthalate } \\
\text { Hexachloro-1,3-butadiene }\end{array}$ & in black inks \\
$\begin{array}{l}\text { Metheneamine } \\
\text { Dibenzofuran }\end{array}$ & {$[12]$} & impurities in black inks \\
Benzophenone & & \\
9-Fluorenone & & \\
3,6-Dimethyl-1 heptyn-3-ol & & \\
1,6-Hexandiole, oleamide & & \\
7-Hexyl-2-oxepanone & & \\
1,1'Oxybis-2-propanol & & \\
1,2,3,4-Tetrahydro-1-phenyl-naphthalene & \\
\hline
\end{tabular}

should thus always lead to further clinical investigation for underlying sarcoidosis [26]. In the articles reviewed, most of the patients with sarcoidal granulomas in their tattoos displayed systemic sarcoidosis $(\mathrm{n}=$ 16), only two case-series comprising 8 patients reported sarcoidal granuloma in tattooed patients without systemic sarcoidosis [27, 28]. In some cases of sarcoidal granuloma, which appeared in multicolored tattoos, the skin reaction was confined to a single tattoo pigment i.e. red, black or blue [27, 29-34].

Other Granulomatous Reactions. The introduction of foreign substances into the skin can promote a toxic or an immunological response and reactions to various tattoo pigments have been described [21, $35,36]$. The timing of these delayed-type hypersensitivity reactions may vary from shortly after the tattoo application up to several years later $[37,38]$, and may be triggered by retattooing.

Comparison to Survey. The results of the survey confirm the case reports, which clearly show more frequent skin reactions (category 1) to colored tattoos (83.3\%) than to black tattoos $(12.5 \%)$. The chemistry of color pigments like azo or polycyclic compounds is quite complex and comprises 
Table 2. Adverse reactions to tattoos

\begin{tabular}{|c|c|c|c|c|}
\hline \multicolumn{5}{|c|}{ Category 1: Allergic, lichenoid or granulomatous reactions } \\
\hline Sarcoidal granuloma & {$[27,34,66-76]$} & 19,25 & $23-54$ & $\begin{array}{l}\text { patients with systemic sarcoidosis: } n=16 \text {, patients } \\
\text { without systemic sarcoidosis: } n=8 \text { and an allergic } \\
\text { cause assumed: } n=1[27]\end{array}$ \\
\hline $\begin{array}{l}\text { Allergic hypersensitivity } \\
\text { reactions (eczematous and } \\
\text { lichenoid reactions) }\end{array}$ & $\begin{array}{l}{[14,15,21,25} \\
37,85-98]\end{array}$ & 19,39 & $19-61$ & $\begin{array}{l}\text { lichenoid tattoo reaction }[15,21,85,86,91-93,96] \text {, } \\
\text { contact dermatitis, positive scratch test }[88] \text {, contact } \\
\text { dermatitis to red color, positive patch test }[89,90 \text {, } \\
92], \text { reaction confined to red tattoo ink }[25] \text { and } \\
\text { contact dermatitis to India ink }[95]\end{array}$ \\
\hline
\end{tabular}

\begin{tabular}{|c|c|c|c|c|}
\hline \multicolumn{5}{|l|}{ Category 2: Infections } \\
\hline Viral warts & {$[43,113-116]$} & 5,5 & $17-37$ & \\
\hline Molluscum contagiosum & [117-119] & 3,3 & $20-24$ & \\
\hline HSV (Herpes compunctorum) & {$[120]$} & 1,1 & 30 & \\
\hline Hepatitis C & {$[121-124]$} & 4,6 & $25-40$ & and epidemiologic articles $[125,126]$ \\
\hline $\begin{array}{l}\text { Inoculation tuberculosis } \\
\qquad(M . \text { tuberculosis complex })\end{array}$ & {$[127-129]$} & 3,4 & $33-40$ & \\
\hline Inoculation leprosy (M. leprae) & {$[130-132]$} & 3,33 & $21-40$ & \\
\hline Nontuberculous mycobacteria & {$[44,133-141]$} & 10,47 & $20-51$ & $\begin{array}{l}\text { often gray color due to dilution with tap water }[138 \\
7 \text { female patients treated by the same cosmetician } \\
\text { [141] }\end{array}$ \\
\hline $\begin{array}{l}\text { CA-MRSA with skin and soft } \\
\text { tissue infections }\end{array}$ & {$[142,143]$} & 2,44 & $15-42$ & $\begin{array}{l}44 \text { recipients of tattoos from } 13 \text { unlicensed tattooist } \\
\text { in } 3 \text { states (Ohio, Kentucky, and Vermont, USA) }\end{array}$ \\
\hline Other bacterial infections & {$[144-149]$} & 5,6 & $18-44$ & $\begin{array}{l}\text { toxic shock syndrome [144], 'necrotizing cutaneous } \\
\text { reaction' }[145] \text {, epidural abscess [146], endocarditis } \\
{[147,148] \text { and polymicrobial septicemia }[149]}\end{array}$ \\
\hline Tinea & {$[45]$} & 1,1 & unknown & \\
\hline Leishmaniasis & {$[150]$} & 1,1 & 30 & $\begin{array}{l}\text { visceral leishmaniasis with cutaneous lesions in } \\
\text { tattoo of an HIV-positive patient }\end{array}$ \\
\hline \multicolumn{5}{|l|}{ Category 3: Tumors } \\
\hline $\mathrm{MM}$ & {$[151-158]$} & 8,8 & $26-56$ & $\begin{array}{l}\text { several case reports of tattoo pigment in sentinel } \\
\text { lymph node mimicking MM }\end{array}$ \\
\hline BCC & {$[54,159-162]$} & 5,6 & $35-72$ & 2 older ladies from Iran: head tattoo \\
\hline SCC & {$[163,164]$} & 2,3 & $30-47$ & \\
\hline KA & {$[165-168]$} & 4,11 & $36-66$ & $\begin{array}{l}\text { in } 82 \% \text { of cases association with red tattoo color } \\
\text { [168] }\end{array}$ \\
\hline Other & {$[47,169-172]$} & 4,5 & $20-41$ & $\begin{array}{l}\text { dermatofibrosarcoma protuberans }[169,172] \text {, } \\
\text { cutaneous leiomyosarcoma }[170] \text { and 'autograft } \\
\text { nevus' [171] }\end{array}$ \\
\hline
\end{tabular}


Table 3. Review of the medical reports listing: sex of patients and tattoo location and color

\begin{tabular}{|c|c|c|c|c|c|c|c|c|c|c|c|}
\hline & $\frac{\text { Patients }}{\text { number }}$ & male & female & $\begin{array}{l}\text { un- } \\
\text { known }\end{array}$ & extremities & trunk & head & $\begin{array}{l}\text { un- } \\
\text { known }\end{array}$ & black & colored & $\begin{array}{l}\text { un- } \\
\text { known }\end{array}$ \\
\hline \multicolumn{12}{|l|}{ Category 1} \\
\hline Allergic reactions & 39 & 25 & 11 & 3 & 14 & 2 & 4 & 19 & 2 & 37 & 0 \\
\hline Sarcoidal granuloma & 25 & 12 & 12 & 1 & 16 & 2 & 3 & 4 & 9 & 12 & 4 \\
\hline Other & 6 & 4 & 2 & 0 & 3 & 2 & 0 & 1 & 1 & 5 & 0 \\
\hline Subtotal & 96 & $58.3 \%$ & $37.5 \%$ & $4.2 \%$ & $50.0 \%$ & $10.4 \%$ & $9.4 \%$ & $30.2 \%$ & $12.5 \%$ & $83.3 \%$ & $4.2 \%$ \\
\hline \multicolumn{12}{|l|}{ Category 2} \\
\hline Lupus vulgaris & 4 & 1 & 3 & 0 & 4 & 0 & 0 & 0 & 3 & 0 & 1 \\
\hline Leprosy & 33 & 0 & 33 & 0 & 30 & 1 & 2 & 0 & 0 & 33 & 0 \\
\hline Hepatitis C & 6 & 3 & 3 & 0 & 0 & 0 & 3 & 3 & 0 & 0 & 6 \\
\hline HSV (Herpes compunctorum) & 1 & 1 & 0 & 0 & 0 & 0 & 0 & 1 & 0 & 0 & 1 \\
\hline Tinea & 1 & 0 & 0 & 1 & 0 & 0 & 0 & 1 & 0 & 0 & 1 \\
\hline Leishmaniasis & 1 & 1 & 0 & 0 & 0 & 0 & 0 & 1 & 0 & 0 & 1 \\
\hline Other bacterial infections & 6 & 4 & 2 & 0 & 2 & 3 & 0 & 1 & 3 & 1 & 2 \\
\hline Subtotal & 151 & $55.6 \%$ & $43.7 \%$ & $0.7 \%$ & $35.1 \%$ & $6.0 \%$ & $7.9 \%$ & $51.0 \%$ & $13.9 \%$ & $31.1 \%$ & $55.0 \%$ \\
\hline \multicolumn{12}{|l|}{ Category 3} \\
\hline KA & 11 & 8 & 3 & 0 & 10 & 1 & 0 & 0 & 0 & 11 & 0 \\
\hline MM & 8 & 7 & 1 & 0 & 4 & 3 & 0 & 1 & 4 & 3 & 1 \\
\hline $\mathrm{BCC}$ & 6 & 3 & 3 & 0 & 1 & 3 & 2 & 0 & 3 & 2 & 1 \\
\hline SCC & 3 & 1 & 2 & 0 & 1 & 0 & 1 & 1 & 1 & 1 & 1 \\
\hline Subtotal & 33 & $72.7 \%$ & $27.3 \%$ & $0 \%$ & $63.6 \%$ & $21.2 \%$ & $9.1 \%$ & $6.1 \%$ & $30.3 \%$ & $54.5 \%$ & $15.2 \%$ \\
\hline Total & 280 & $58.6 \%$ & $39.6 \%$ & $1.8 \%$ & $43.6 \%$ & $9.3 \%$ & $8.6 \%$ & $38.6 \%$ & $15.4 \%$ & $51.8 \%$ & $32.9 \%$ \\
\hline
\end{tabular}

many hazardous substances that have the potential to provoke adverse skin reactions. The high frequency of adverse reactions to colored inks is of particular importance, because colored tattoos comprise about $40 \%$ of tattoos, less frequent than black tattoos (about 60\%). The case reports show more frequent problems in males $(58.3 \%)$ than in females $(37.5 \%)$. This is contrary to the survey, in which males reported less adverse reactions associated with tattoos than females. On the one hand, this might be due to attitudes, with males underplaying problems with tattoos. On the other hand, the number of patients in the case reports of category $1(n=96)$ is clearly smaller than in the survey $(\mathrm{n}=3,411)$ [18]. The survey showed that $45.2 \%$ of people have tattoos on the trunk, $50.8 \%$ on the extremities and $2.7 \%$ on the head and neck. When review- ing the medical reports (table 3), a much higher incidence of adverse reactions is reported for the extremities (50.0\%) than for the trunk (10.4\%). In addition, the head as a tattoo location is mentioned an aboveaverage number of times, possibly due to the reported cases of reaction to permanent make-up. As $30.2 \%$ of the adverse reactions were not assigned to a specific location, it remains difficult to assess these contradictory results. Some of the substances (table 1) in tattoo inks (e.g. PAHs and phthalocyanines) are excellent photosensitizers that can generate reactive oxygen species [13] in tattooed skin exposed to light. We could tentatively speculate that tattoos on the head and extremities are more frequently exposed to solar radiation, which might be what causes a higher rate of adverse reactions.

\section{Category 2: Infections}

Tattooing entails physical injury of relatively large skin areas that may promote the transdermal transmission of viral and bacterial infections, depending on the conditions of hygiene during tattooing [39]. In most of the published case reports, insufficient or a complete lack of sterilization procedures in the tattoo parlors was regarded as responsible for the transmission of infectious diseases. There are 3 potential origins of infections after tattooing. Firstly, the tattoo ink itself can be contaminated, especially by bacterial pathogens. Secondly, in the case of an inadequate disinfection of the skin area to be tattooed, residential bacteria can enter the skin during the tattooing process. Thirdly, during the healing process of the injured tissue after tattooing, patients often notice pruritus and 
burning [18], with the risk of superinfecting the tattooed skin area due to scratching and therefore inoculating microorganisms (fig. 2b).

Viral Diseases. According to epidemiological studies and case reports, there is strong evidence for the transmission of hepatitis $B$ and $C$ virus infections from tattooing (table 2). Tattooing could also, theoretically, transmit the human immunodeficiency virus (HIV) [40-42], although we found no cases of HIV infection in the literature directly related to tattooing. Cutaneous infections caused by human papillomavirus (HPV) include common, plantar and juvenile warts. Cases of HPV infection have been observed due to transmission of the virus during the process of tattooing or the presence of HPV in the tattoo dye. In one case, a 32-year-old man experienced development of multiple warts restricted to the tattooed area after sunburn damage. The tattoo had been performed 2.5 years previously, so in this case, HPV persisted asymptomatically for a long period before activation by local UV-induced immunosuppression resulting in multiple warts [43]. There are also reports on the appearance of Molluscum contagiosum caused by Poxviridae and of Herpes simplex virus (HSV) infection in tattooed areas, also via transmission during the tattooing process (see category 2, table 2 ).

Bacterial Infections. Reported cases on bacterial infections related to tattooing comprise - among others - Streptococcus pyogenes leading to impetigo, erysipelas and even septicemia, Staphylococcus aureus causing the rare toxic shock syndrome, skin and soft tissue infections caused by community-acquired methicillin-resistant Staphylococcus aureus (CA-MRSA), infections with atypical mycobacteria and even Mycobacterium leprae which causes leprosy. These bacterial infectious complications are caused by insufficient personal hygiene or lack of hygiene control measures in the tattooing process. Although hygiene in tattoo parlors has improved, official inspection is still rare. In recent years, several reports of infections with atypical mycobacteria after tattooing were published [44]. A few cases of leprosy after tattooing in India were caused by insufficiently hygienic conditions during the tattooing process, which had been performed by roadside tattooists. There was only one report on cutaneous fungal infections in the literature reviewed [45] and a ophthalmologic report of a 40-year-old asplenic man with Candida albicans endophthalmitis of the right eye 1 week after tattooing [46].

Comparison to Survey. The detailed results of the survey showed that about $0.5 \%$ of tattooed participants suffered from infections manifesting as pus-filled skin areas [18]. As about 8 million people in Germany have tattoos, we estimate that about 40,000 people would have had bacterial infections in the tattooed skin area. These data fit with the high number of reported bacterial infections in the literature (table 3 ), in particular when extrapolating this number to other countries. The survey showed that the person's sex played no role for the risk of developing pyogenic bacterial infections. The case reports in the literature proposed a slightly higher number of male patients affected by bacterial infections than females. Again, tattoos performed on the extremities are more frequently involved in bacterial infections than those on the trunk. Unfortunately, in the literature, location was not provided in more than half of the cases. When asked about hepatitis, about $0.6 \%$ of the survey participants reported a positive test shortly after tattooing, but causality cannot be claimed here.

\section{Category 3: Tumors}

The occurrence of benign tumors like seborrheic keratosis, histiocytofibroma, epidermal cysts and milia after tattooing is well known; cases are only rarely published [47].

Several malignant lesions have occurred in tattoos including basal cell carcinoma (BCC), keratoacanthoma (KA), squamous cell carcinoma (SCC), malignant melanoma (MM) and dermatofibrosarcoma protuberans (table 2). MM has been reported to occur in tattoos, vaccination scars and tattoo sites used for radiotherapy field marking. To our knowledge, there are only 8 documented cases of MM after tattooing in the medical literature during the years reviewed (1991-2011), but there are several case reports on tattoo pigment in sentinel lymph node biopsies mimicking MM [4, 8, 48, 49]. In all these cases, the migration of tattoo pigments via lymphatic drainage was initially considered as evidence for metastatic tumors until proper histopathological examination. Meanwhile, the transportation of tattoo inks, admixtures and impurities from the skin to the lymph nodes is a well-known fact $[3,8,50]$. Tattooists often also tattoo into pre-existing nevi and pigmented lesions, thus impeding a correct clinical and dermatoscopic evaluation $[51,52]$.
BCC has been rarely found to appear after trauma, for example in surgical scars [53]. This is also the case with KA. Engel et al. [54] made quite an interesting observation. They reported an uncommon case of BCC of the thumb of a 58-year-old man due to an azo-pigment-containing colorant repeatedly used as a marker of fishing bait. The authors stated that azo pigment in the colorants can be cleaved to carcinogenic amines under light exposure, in particular after incorporation into the human body.

In view of the large number of people that have tattoos and the few cases of malignant lesions that have been reported so far, at present, the association might be coincidental. Numerous factors could be involved, including intradermal injection of potentially carcinogenic substances, exposure to UV radiation and genetic factors. Recently, high amounts of PAH such as benz(a)pyrene were detected in commercially available black tattoo inks [13]; these obviously enter the skin along with the black ink. At the same time, about $10 \%$ of the participants in our study reported having melanocytic nevi within tattooed skin areas. Whether the injection of such hazardous substances might affect melanocytic nevi is unclear so far and should be determined by means of epidemiological studies.

It is to be kept in mind that dark black tattoos cannot only impede a correct clinical and dermatoscopic evaluation, but can also mask the development of new melanocytic lesions or the change of existing nevi. Physicians should report all skin tumors which they observe in tattooed skin.

Comparison to Survey. Skin cancer associated with tattooed skin was rarely reported in the survey $(0.1 \%$, all male $)$, which was equivalent to about 8,000 cases in Germany. The review of medical reports shows that 24 patients with tumors in tattooed skin were male (24/33). The affected tattoo was mainly colored (18/33), which again confirms that colored tattoos cause more adverse reactions than black tattoos (see also category 1, table 3 ). Again, the extremities and head (total: $72.9 \%$ ) were more frequently involved as locations than the trunk. Exposure of tattoos to solar radiation might also play a role.

\section{Miscellaneous Cutaneous}

\section{Complications after Tattooing}

Several articles reported a flare of an isomorphic Koebner response after tattoo application in patients with active susceptible disease, e.g. psoriasis [55-57], lichen 
planus and vitiligo. Punzi et al. [56] reported a 26-year-old male patient who developed psoriasis plaques in a tattoo 1 week after tattooing by an amateur. Subacute cutaneous and discoid lupus erythematosus following dermal injury during tattoo placement and pyoderma gangrenosum have also been described [58-61].

Although lichen planus lesions can theoretically develop in tattooed skin, they are difficult to differentiate from the lichenoid reactions described above and therefore we found no specific report on this diagnosis.

\section{Conclusions}

When comparing the results of the survey with the data of the reviewed case reports, there are some concurring and some contradictory results. However, the comparisons clearly show that colored tattoo pigments more frequently cause skin problems that are associated with granulomatous, lichenoid or hypersensitivity allergic reactions and even skin tumors.

It is also very interesting that the reported skin problems are clearly more frequent for tattoos on the extremities than for those on the trunk, even though the frequency of tattooing is nearly the same for both locations. As photosensitizing agents were detected in tattoo inks, the more frequent exposure of the extremities to solar radiation might have been a contributing factor.

The review of published case reports show that the cause of the skin reactions was mainly investigated by histopathology. In the case of allergic or granulomatous reactions, in general, no further testing was applied to establish what triggered such reactions. However, diagnostic procedures to prove allergic reactions to tattoo colors remain challenging due to the numerous and usually unknown substances in the tattoo inks. So patch testing, as performed in several studies to confirm the diagnosis 'allergic reaction', might not be the appropriate approach. Subsequently, many authors limit their diagnosis to the histopathological pattern (e.g. 'granulomatous type IVreaction') without a definite clinical diagnosis. This reflects the problematic interpretation of the observed 'patterns' and also hampers effective regulating of the use of tattoo inks by legislation. In the case of infections, hygiene plays an important role, which includes the tattooing practice and the purity of the used tattoo inks.

The most important issue, the possible role of tattoo inks in the formation of tumors, is unclear so far. The review retrospectively considers the medical reports of the past 20 years (1991-2011). In view of the latency period for carcinogenesis, this time span should be correlated to the tattooing practice in the decades prior to this period. Tattooing has become increasingly popular in this period and the chemistry of tattoo inks has changed. The results may change within the next 20 years. It is obvious that well-known mutagenic or carcinogenic substances like PAHs and many amines should not be present in tattoo inks.

In the light of these results, in particular those regarding colored inks, we urgently recommend the regulation of tattoo inks that leads to application of inks that do not contain hazardous substances. A first step would be: the substances that are not allowed to be used in cosmetics on top of the skin should certainly not be allowed to enter the skin via the puncturing involved in tattoos.

\section{References}

1 Dorfer L, Moser M, Bahr F, Spindler K, Egarter-Vigl E, Giullen S, Dohr G, Kenner T: A medical report from the Stone Age? Lancet 1999;354:1023-1025.

$\longrightarrow 2$ Ortiz AE, Alster TS: Rising concern over cosmetic tattoos. Dermatol Surg 2012;38:424-429.

- 3 Engel E, Vasold R, Santarelli F, Maisch T, Gopee NV, Howard PC, Landthaler M, Baumler W: Tattooing of skin results in transportation and light-induced decomposition of tattoo pigments - a first quantification in vivo using a mouse model. Exp Dermatol 2010;19:54-60.

4 Anderson LL, Cardone JS, McCollough ML, Grabski WJ: Tattoo pigment mimicking metastatic malignant melanoma. Dermatol Surg 1996;22:92-94.

5 Bordea C, Latifaj B, Jaffe W: Delayed presentation of tattoo lymphadenopathy mimicking malignant melanoma lymphadenopathy. J Plast Reconstr Aesthet Surg 2009;62:e283e285.

6 Jaigirdar AA, Yeh MW, Sharifi E, Browne LW, Leong SP: Coexisting tattoo pigment and metastatic melanoma in the same sentinel lymph node. J Cutan Med Surg 2009;13:321325.

7 Kurle S, Schulte KW, Homey B: Accumulation of tattoo pigment in sentinel lymph nodes. Hautarzt 2009;60:781-783.
-8 Moehrle M, Blaheta HJ, Ruck P: Tattoo pigment mimics positive sentinel lymph node in melanoma. Dermatology 2001;203:342344.

9 Schlager A, Laser A, Melamed J, Guth AA: A tattoo-pigmented node masquerading as the sentinel node in a case of breast cancer. Breast J 2008;14:299-300.

10 Zirkin HJ, Avinoach I, Edelwitz P: A tattoo and localized lymphadenopathy: a case report. Cutis 2001;67:471-472.

11 Wenzel SM, Welzel J, Hafner C, Landthaler M, Baumler W: Permanent make-up colorants may cause severe skin reactions. Contact Dermatitis 2010;63:223-227.

12 Lehner K, Santarelli F, Vasold R, Konig B, Landthaler M, Baumler W: Black tattoo inks are a source of problematic substances such as dibutyl phthalate. Contact Dermatitis 2011; 65:231-238.

13 Regensburger J, Lehner K, Maisch T, Vasold R, Santarelli F, Engel E, Gollmer A, Konig B, Landthaler M, Baumler W: Tattoo inks contain polycyclic aromatic hydrocarbons that additionally generate deleterious singlet oxygen. Exp Dermatol 2010;19:e275-e281.

14 Jaeger C, Jappe U: Manifestation einer Nickelallergie als Kontaktdermatitis auf Permanent-Make-up. J Dtsch Dermatol Ges 2005;3: 527-529.
15 Corazza M, Zampino MR, Montanari A, Pagnoni A, Virgili A: Lichenoid reaction from a permanent red tattoo: has nickel a possible aetiologic role? Contact Dermatitis 2002;46: 114-115.

16 Baier J, Maisch T, Maier M, Engel E, Landthaler M, Baumler W: Singlet oxygen generation by UVA light exposure of endogenous photosensitizers. Biophys J 2006;91:1452-1459.

17 Huxley C, Grogan S: Tattooing, piercing, healthy behaviours and health value. J Health Psychol 2005;10:831-841.

18 Klugl I, Hiller KA, Landthaler M, Baumler W: Incidence of health problems associated with tattooed skin: a nation-wide survey in German-speaking countries. Dermatology 2010; 221:43-50.

19 Baumler W, Eibler ET, Hohenleutner U, Sens B, Sauer J, Landthaler M: Q-switch laser and tattoo pigments: first results of the chemical and photophysical analysis of 41 compounds. Lasers Surg Med 2000;26:13-21.

20 Amann U, Luger TA, Metze D: Lichenoid pseudolymphomatous tattooing reaction. Hautarzt 1997;48:410-413.

-21 Litak J, Ke MS, Gutierrez MA, Soriano T, Lask GP: Generalized lichenoid reaction from tattoo. Dermatol Surg 2007;33:736-740. 
22 Chave TA, Mortimer NJ, Johnston GA: Simultaneous pseudolymphomatous and lichenoid tattoo reactions triggered by re-tattooing. Clin Exp Dermatol 2004;29:197-199.

23 Gutermuth J, Hein R, Fend F, Ring J, Jakob T: Cutaneous pseudolymphoma arising after tattoo placement. J Eur Acad Dermatol Venereol 2007;21:566-567.

24 Mortimer NJ, Chave TA, Johnston GA: Red tattoo reactions. Clin Exp Dermatol 2003;28: 508-510.

25 Cook J, Metcalf J: Images in clinical medicine. Tattoo allergy. N Engl J Med 2009;361:e1.

-26 Kluger N: Cutaneous complications related to permanent decorative tattooing. Expert Rev Clin Immunol 2010;6:363-371.

-27 Morales-Callaghan AM Jr, Aguilar-Bernier M Jr, Martinez-Garcia G, Miranda-Romero A: Sarcoid granuloma on black tattoo. J Am Acad Dermatol 2006;55:S71-S73.

28 Ghorpade A: Inoculation sarcoidal granulomas on blue-black tattoos in seven ladies. J Eur Acad Dermatol Venereol 2006;20:349350.

29 Ali SM, Gilliam AC, Brodell RT: Sarcoidosis appearing in a tattoo. J Cutan Med Surg 2008; 12:43-48.

30 Papageorgiou PP, Hongcharu W, Chu AC: Systemic sarcoidosis presenting with multiple tattoo granulomas and an extra-tattoo cutaneous granuloma. J Eur Acad Dermatol Venereol 1999;12:51-53.

-31 Jones MS, Maloney ME, Helm KF: Systemic sarcoidosis presenting in the black dye of a tattoo. Cutis 1997;59:113-115.

32 Collins P, Evans AT, Gray W, Levison DA: Pulmonary sarcoidosis presenting as a granulomatous tattoo reaction. Br J Dermatol 1994; 130:658-662.

- 33 Sowden JM, Cartwright PH, Smith AG, Hiley C, Slater DN: Sarcoidosis presenting with a granulomatous reaction confined to red tattoos. Clin Exp Dermatol 1992;17:446-448.

- 34 Colp CR, Goldfarb R, Ongseng F: Value of gallium imaging in the evaluation of tattoo granulomas due to sarcoidosis. Chest 1991; 100:1737-1738.

- 35 Bendsoe N, Hansson C, Sterner O: Inflammatory reactions from organic pigments in red tattoos. Acta Derm Venereol 1991;71:70-73.

-36 Balfour E, Olhoffer I, Leffell D, Handerson T: Massive pseudoepitheliomatous hyperplasia: an unusual reaction to a tattoo. Am J Dermatopathol 2003;25:338-340.

- 37 Duke D, Urioste SS, Dover JS, Anderson RR: A reaction to a red lip cosmetic tattoo. J Am Acad Dermatol 1998;39:488-490.

-38 Goldstein N: Mercury-cadmium sensitivity in tattoos. A photoallergic reaction in red pigment. Ann Intern Med 1967;67:984-989.

- 39 Kluger N, Terru D, Godreuil S: Bacteriological and fungal survey of commercial tattoo inks used in daily practice in a tattoo parlour. J Eur Acad Dermatol Venereol 2011;25:12301231.
40 Heudorf U, Kutzke G, Seng U: Tattooing and body piercing - experiences from public health infection surveillance by a public health office. Gesundheitswesen 2000;62: 219-224.

41 Hellard ME, Aitken CK, Hocking JS: Tattooing in prisons - not such a pretty picture. Am J Infect Control 2007;35:477-480.

42 Nishioka Sde A, Gyorkos TW, Joseph L, Collet JP, Maclean JD: Tattooing and risk for transfusion-transmitted diseases: the role of the type, number and design of the tattoos, and the conditions in which they were performed. Epidemiol Infect 2002;128:63-71.

43 Brajac I, Loncarek K, Stojnic-Sosa L, Gruber F: Delayed onset of warts over tattoo mark provoked by sunburn. J Eur Acad Dermatol Venereol 2005;19:247-248.

-44 Kluger N, Muller C, Gral N: Atypical mycobacteria infection following tattooing: review of an outbreak in 8 patients in a French tattoo parlor. Arch Dermatol 2008;144:941-942.

45 Ammirati CT: What is your diagnosis? Tinea in tattoo. Cutis 2004;73:228, 232.

46 Alexandridou A, Reginald AY, Stavrou P, Kirkby GR: Candida endophthalmitis after tattooing in an asplenic patient. Arch Ophthalmol 2002;120:518-519.

47 Kluger N, Cotten H, Magana C, Pinquier L: Dermatofibroma occurring within a tattoo: report of two cases. J Cutan Pathol 2008;35: 696-698.

48 Hannah H, Falder S, Steele PR, Dhital SK: Tattoo pigment masquerading as secondary malignant melanoma. Br J Plast Surg 2000;53:359.

49 Kluger N, Koljonen V: Tattoos, inks, and cancer. Lancet Oncol 2012;13:e161-e168.

50 Kluger N, Cohen-Valensi R, Nezri M: Black lymph nodes - and a colourful skin. Lancet 2008;371:1214.

51 Gall N, Brocker EB, Becker JC: Particularities in managing melanoma patients with tattoos: case report and review of the literature. J Dtsch Dermatol Ges 2007;5:1120-1121.

52 Kluger N, Catala D, Thibaut I: Naevus and tattooing: a matter of concern. J Eur Acad Dermatol Venereol 2008;22:767-768.

53 Ozyazgan I, Kontacs O: Basal cell carcinoma arising from surgical scars: a case and review of the literature. Dermatol Surg 1999;25:965968.

54 Engel E, Ulrich H, Vasold R, Konig B, Landthaler M, Suttinger R, Baumler W: Azo pigments and a basal cell carcinoma at the thumb. Dermatology 2008;216:76-80.

55 Jacob CI: Tattoo-associated dermatoses: a case report and review of the literature. Dermatol Surg 2002;28:962-965.

56 Punzi L, Rizzi E, Pianon M, Rossini P, Gambari PF: Tattooing-induced psoriasis and psoriatic arthritis. Br J Rheumatol 1997;36:11331134.

57 Horner KL, Chien AJ, Edenholm M, Hornung RL: Winnie the Pooh and psoriasis too: an isomorphic response of guttate psoriasis in a tattoo. Pediatr Dermatol 2007;24:E70-E72.
58 La Placa M, Passarini B: Subacute cutaneous lupus erythematosus after a tattoo. Clin Exp Dermatol 2009;34:632-633.

59 Jacobson S, Martin DB, Deng A, Cooper JZ: Pyoderma gangrenosum following tattoo placement in a patient with acute myelogenous leukemia. J Dermatolog Treat 2008; 19 : 58-60.

60 Jolly M: Discoid lupus erythematosus after tattoo: Koebner phenomenon. Arthritis Rheum 2005;53:627.

61 Tendas A, Niscola P, Barbati R, Abruzzese E, Cuppelli L, Giovannini M, Scaramucci L, Fratoni S, Ales M, Neri B, Morino L, Dentamaro T, De Fabritiis P: Tattoo related pyoderma/ectyma gangrenous as presenting feature of relapsed acute myeloid leukaemia: an exceptionally rare observation. Injury 2011;42:546-547.

62 Lehmann G, Pierchalla P: Tattooing dyes. Derm Beruf Umwelt 1988;36:152-156.

63 Beute TC, Miller CH, Timko AL, Ross EV: In vitro spectral analysis of tattoo pigments. Dermatol Surg 2008;34:508-515; discussion 515-516.

64 Hogsberg T, Loeschner K, Lof D, Serup J: Tattoo inks in general usage contain nanoparticles. Br J Dermatol 2011;165:1210-1218.

65 Vasold R, Naarmann N, Ulrich H, Fischer D, Konig B, Landthaler M, Baumler W: Tattoo pigments are cleaved by laser light - the chemical analysis in vitro provide evidence for hazardous compounds. Photochem Photobiol 2004; 80: 185-190.

-66 de Geus HR, Giard RW, Jacobs FA, Lonnee ER, Dees A: Abnormalities in tattooed skin: sometimes sarcoidosis. Ned Tijdschr Geneeskd 2005; 149:1113-1117.

67 Toulemonde A, Quereux G, Dreno B: Sarcoidosis granuloma on a tattoo induced by interferon alpha. Ann Dermatol Venereol 2004; 131:49-51.

68 Tran D, Ashton RE, Cotterill JA: Sarcoidosis presenting as tattoo granuloma inadvertently treated with laser therapy. J Cutan Laser Ther 2000;2:41-43.

-69 Nawras A, Alsolaiman MM, Mehboob S, Bartholomew C, Maliakkal B: Systemic sarcoidosis presenting as a granulomatous tattoo reaction secondary to interferon-alpha treatment for chronic hepatitis $\mathrm{C}$ and review of the literature. Dig Dis Sci 2002;47:1627-1631.

70 Werchniak AE, Cheng SX, Dhar AD, Klaus $\mathrm{SN}$ : Sarcoidosis presenting as tattoo changes in a patient undergoing treatment with interferon-alpha and ribavirin. Clin Exp Dermatol 2004;29:547-548.

71 Antonovich DD, Callen JP: Development of sarcoidosis in cosmetic tattoos. Arch Dermatol 2005; $141: 869-872$

72 Murdoch SR, Fenton DA: Sarcoidosis presenting as nodules in both tattoos and scars. Clin Exp Dermatol 1997;22:254-255.

73 Yesudian PD, Azurdia RM: Scar sarcoidosis following tattooing of the lips treated with mepacrine. Clin Exp Dermatol 2004;29:552554 
74 Baumgartner M, Feldmann R, Breier F, Steiner A: Sarcoidal granulomas in a cosmetic tattoo in association with pulmonary sarcoidosis. J Dtsch Dermatol Ges 2010;8:900-902.

75 Anolik R, Mandal R, Franks AG Jr: Sarcoidal tattoo granuloma. Dermatol Online J 2010; 16:19.

-76 Yoong C, Vun YY, Spelman L, Muir J: True blue football fan: tattoo reaction confined to blue pigment. Australas J Dermatol 2010;51: 21-22.

77 Wollina U, Gruner M, Schonlebe J: Granulomatous tattoo reaction and erythema nodosum in a young woman: common cause or coincidence? J Cosmet Dermatol 2008; 7:84-88.

-78 Barabasi Z, Kiss E, Balaton G, Vajo Z: Cutaneous granuloma and uveitis caused by a tattoo. Wien Klin Wochenschr 2008;120:18.

-79 Bachmeyer C, Blum L, Petitjean B, Kemiche F, Pertuiset E: Granulomatous tattoo reaction in a patient treated with etanercept. J Eur Acad Dermatol Venereol 2007;21:550-552.

-80 Jones B, Oh C, Egan CA: Spontaneous resolution of a delayed granulomatous reaction to cosmetic tattoo. Int J Dermatol 2008;47:5960.

81 Wylie G, Gupta G: Lip-enhancing tattoo reaction resolving with topical tacrolimus. Clin Exp Dermatol 2008;33:505-506.

82 Tope WD, Arbiser JL, Duncan LM: Black tattoo reaction: the peacock's tale. J Am Acad Dermatol 1996;35:477-479.

83 Bagwan IN, Walker M, Theaker JM: Granuloma annulare-like tattoo reaction. J Cutan Pathol 2007;34:804-805.

84 Sweeney SA, Hicks LD, Ranallo N, Iv NS, Soldano AC: Perforating granulomatous dermatitis reaction to exogenous tattoo pigment: a case report and review of the literature. Am J Dermatopathol 2011, Epub ahead of print.

85 Campbell FA, Gupta G: Lichenoid tattoo reaction responding to topical tacrolimus ointment. Clin Exp Dermatol 2006;31:293-294.

-86 Steinbrecher I, Hemmer W, Jarisch R: Adverse reaction to the azo dye pigment red 170 in a tattoo. J Dtsch Dermatol Ges 2004; 2: $1007-1008$.

87 Schulz J, Lonsdorf A, Jappe U, Hartschuh W: Disseminated granulomatous type IV reaction after a tattoo. Hautarzt 2008;59:567-570.

88 Greve B, Chytry R, Raulin C: Contact dermatitis from red tattoo pigment (quinacridone) with secondary spread. Contact Dermatitis 2003; 49:265-266.

89 Bhardwaj SS, Brodell RT, Taylor JS: Red tattoo reactions. Contact Dermatitis 2003; 48: 236-237.

90 Pauluzzi P, Giordani M, Guarneri GF, Pascone M: Chronic eczematous reaction to red tattoo. J Eur Acad Dermatol Venereol 1998; 11:187-188.

91 Sowden JM, Byrne JP, Smith AG, Hiley C, Suarez V, Wagner B, Slater DN: Red tattoo reactions: $\mathrm{X}$-ray microanalysis and patch-test studies. Br J Dermatol 1991;124:576-580.
\$2 Tresukosol P, Ophaswongse S, Kullavanijaya P: Cutaneous reaction to cosmetic lip tattooing. Contact Dermatitis 1997;36:176177.

93 Zwad J, Jakob A, Gross C, Rompel R: Treatment modalities for allergic reactions in pigmented tattoos. J Dtsch Dermatol Ges 2007; 5:8-13.

94 Yazdian-Tehrani H, Shibu MM, Carver NC: Reaction in a red tattoo in the absence of mercury. Br J Plast Surg 2001;54:555-556.

$\checkmark 95$ Gallo R, Parodi A, Cozzani E, Guarrera M: Allergic reaction to India ink in a black tattoo. Contact Dermatitis 1998;38:346-347.

96 Cruz FA, Lage D, Frigerio RM, Zaniboni MC, Arruda LH: Reactions to the different pigments in tattoos: a report of two cases. An Bras Dermatol 2010;85:708-711.

97 Harper J, Losch AE, Otto SG, Zirwas M, Delaney KO, Wakelin JK 3rd: New insight into the pathophysiology of tattoo reactions following laser tattoo removal. Plast Reconstr Surg 2010;126:313e-314e.

-98 Jacob SE, Castanedo-Tardan MP, Blyumin ML: Inflammation in green (chromium) tattoos during patch testing. Dermatitis 2008; 19:E33-E34.

99 Blumental G, Okun MR, Ponitch JA: Pseudolymphomatous reaction to tattoos. Report of three cases. J Am Acad Dermatol 1982;6:485-488.

100 Kahofer P, El Shabrawi-Caelen L, Horn M, Kern T, Smolle J: Pseudolymphoma occurring in a tattoo. Eur J Dermatol 2003; 13 : 209-212.

101 Cui W, McGregor DH, Stark SP, Ulusarac O, Mathur SC: Pseudoepitheliomatous hyperplasia - an unusual reaction following tattoo: report of a case and review of the literature. Int J Dermatol 2007; 46:743-745.

102 Munoz C, Guilabert A, Mascaro JM Jr, Lopez-Lerma I, Vilaplana J: An embossed tattoo. Clin Exp Dermatol 2006;31:309-310.

103 Rijlaarsdam JU, Bruynzeel DP, Vos W, Meijer CJ, Willemze R: Immunohistochemical studies of lymphadenosis benigna cutis occurring in a tattoo. Am J Dermatopathol 1988; 10:518-523.

104 Kuo WE, Richwine EE, Sheehan DJ: Pseudolymphomatous and lichenoid reaction to a red tattoo: a case report. Cutis 2011;87:8992.

105 Kluger N, Vermeulen C, Moguelet P, Cotten H, Koeb MH, Balme B, Fusade T: Cutaneous lymphoid hyperplasia (pseudolymphoma) in tattoos: a case series of seven patients. J Eur Acad Dermatol Venereol 2010;24:208213.

106 Hessert MJ, Devlin J: Ink sick: tattoo ink hypersensitivity vasculitis. Am J Emerg Med 2011;29: 1237.e3-1237.e4.

107 Hermida MD, Otero M, Della Giovanna P, Garcia S, Cabrera HN: Cutaneous vasculitis following an intradermal tattoo. J Eur Acad Dermatol Venereol 2007;21:1268-1269.
108 Arun B, Jamieson L, Mendonca C: An unusual presentation of lichen sclerosus et atrophicus in a tattoo. Clin Exp Dermatol 2010;35:441.

109 Kluger N, Mathelier-Fusade P, Moguelet P: Scleroderma-like reaction restricted to the red parts of a tattoo. Acta Derm Venereol 2009;89:95-96.

110 Kluger N, Jolly M, Guillot B: Tattoo-induced vasculitis. J Eur Acad Dermatol Venereol 2008;22:643-644; author reply 644-645.

111 Kluger N: Tattoo-induced vasculitis: is it really the ink? Am J Emerg Med 2011;29:347.

112 Jolly M, Danila MI: Tattoo: inflicted vasculitis? J Clin Rheumatol 2007;13:49.

113 Trefzer U, Schmollack KP, Stockfleth E, Sterry W, Kolde G: Verrucae in a multicolored decorative tattoo. J Am Acad Dermatol 2004;50:478-479.

114 Saez M, Rodriguez-Martin M, Sidro-Sarto M, Cabrera de Paz R, Rodriguez-Garcia F, Fagundo-Gonzalez E, Carnerero A, Guimera F, Garcia-Bustinduy M, Sanchez R, Martin Herrera A, Noda A: Multiple verrucae vulgaris in a young woman's tattoo. J Eur Acad Dermatol Venereol 2006;20:356-357.

115 Miller DM, Brodell RT: Verruca restricted to the areas of black dye within a tattoo. Arch Dermatol 1994;130:1453-1454.

116 Ragland H, Hubbell C, Stewart K, Nesbitt L: Verruca vulgaris inoculated during tattoo placement. Int J Dermatol 1994;33:796-797.

117 Perez Gala S, Alonso Perez A, Rios Buceta L, Aragues Montanes M, Garcia Diez A: Molluscum contagiosum on a multicoloured tattoo. J Eur Acad Dermatol Venereol 2006;20: 221-222.

118 Kluger N, Comte C, Guillot B: Molluscum contagiosum on a tattoo. Ann Dermatol Venereol 2007; 134:506-507.

119 Salmaso F, Gnecchi L, Gianotti R, Veraldi S: Molluscum contagiosum on a tattoo. Acta Derm Venereol 2001;81:146-147.

120 Marshall CS, Murphy F, McCarthy SE, Cheng AC: Herpes compunctorum: cutaneous herpes simplex virus infection complicating tattooing. Med J Aust 2007; 187:598.

121 Post JJ, Dolan KA, Whybin LR, Carter IW, Haber PS, Lloyd AR: Acute hepatitis C virus infection in an Australian prison inmate: tattooing as a possible transmission route. Med J Aust 2001; 174: 183-184.

122 Abildgaard N, Peterslund NA: Hepatitis C virus transmitted by tattooing needle. Lancet 1991;338:460.

123 Sun DX, Zhang FG, Geng YQ, Xi DS: Hepatitis $\mathrm{C}$ transmission by cosmetic tattooing in women. Lancet 1996;347:541.

124 Thompson SC, Hernberger F, Wale E, Crofts $\mathrm{N}$ : Hepatitis $\mathrm{C}$ transmission through tattooing: a case report. Aust N Z J Public Health 1996;20:317-318.

125 Franz R: Tattooing a major route of hepatitis C infection. Dermatol Nurs 2001; 13:307308. 
126 Haley RW, Fischer RP: Commercial tattooing as a potentially important source of hepatitis $\mathrm{C}$ infection. Clinical epidemiology of 626 consecutive patients unaware of their hepatitis C serologic status. Medicine (Baltimore) 2001;80:134-151.

-127 Ghorpade A: Lupus vulgaris over a tattoo mark - inoculation tuberculosis. J Eur Acad Dermatol Venereol 2003; 17:569-571.

128 Ghorpade A: Tattoo inoculation lupus vulgaris in two Indian ladies. J Eur Acad Dermatol Venereol 2006;20:476-477.

129 Wong HW, Tay YK, Sim CS: Papular eruption on a tattoo: a case of primary inoculation tuberculosis. Australas J Dermatol 2005; 46:84-87.

130 Ghorpade A: Inoculation (tattoo) leprosy: a report of 31 cases. J Eur Acad Dermatol Venereol 2002; 16:494-499.

131 Ghorpade A: Reactional tattoo inoculation borderline tuberculoid leprosy with oedematous tattoos. Lepr Rev 2004;75:91-94.

132 Ghorpade A: Ornamental tattoos and skin lesions. Tattoo inoculation borderline tuberculoid leprosy. Int J Dermatol 2009;48: 11-13.

133 De Quatrebarbes J, Pestel-Caron M, DuvalModeste AB, Abboud P, Etienne M, Caron F, Joly P: Epidémie à Mycobacterium chelonae chez un tatoueur. Ann Dermatol Venereol 2005; 132:224-225.

-134 Drage LA, Ecker PM, Orenstein R, Phillips PK, Edson RS: An outbreak of Mycobacterium chelonae infections in tattoos. J Am Acad Dermatol 2010;62:501-506.

135 Wolf R, Wolf D: A tattooed butterfly as a vector of atypical mycobacteria. J Am Acad Dermatol 2003;48:S73-S74.

-136 Preda VA, Maley M, Sullivan JR: Mycobacterium chelonae infection in a tattoo site. Med J Aust 2009; 190:278-279.

-137 Bechara C, Macheras E, Heym B, Pages A, Auffret N: Mycobacterium abscessus skin infection after tattooing: first case report and review of the literature. Dermatology 2010; 221:1-4.

138 Kappel S, Cotliar J: Inoculation of Mycobacteria chelonae from a tattoo. J Am Acad Dermatol 2011;64:998-999.

139 Mitchell CB, Isenstein A, Burkhart CN, Groben P, Morrell DS: Infection with Mycobacterium immunogenum following a tattoo. J Am Acad Dermatol 2011;64:e70-e71.

140 Ricciardo B, Weedon D, Butler G: Mycobacterium abscessus infection complicating a professional tattoo. Australas J Dermatol 2010;51:287-289.

141 Hamsch C, Hartschuh W, Enk A, Flux K: A Chinese tattoo paint as a vector of atypical mycobacteria-outbreak in 7 patients in Germany. Acta Derm Venereol 2011;91:63-64.
142 Centers for Disease Control and Prevention (CDC): Methicillin-resistant Staphylococcus aureus skin infections among tattoo recipients - Ohio, Kentucky, and Vermont, 20042005. MMWR Morb Mortal Wkly Rep 2006; 55:677-679.

143 Stemper ME, Brady JM, Qutaishat SS, Borlaug G, Reed J, Reed KD, Shukla SK: Shift in Staphylococcus aureus clone linked to an infected tattoo. Emerg Infect Dis 2006; 12: 1444-1446.

144 Cowan RK, Martens MG: Toxic shock syndrome mimicking pelvic inflammatory disease presumably resulting from tattoo. South Med J 1993;86:1427-1431.

145 Bhogal RH, Thomas SS: Necrotizing black tattoo reaction: what's in a name? Am J Clin Dermatol 2009; 10:131-133.

146 Chowfin A, Potti A, Paul A, Carson P: Spinal epidural abscess after tattooing. Clin Infect Dis 1999;29:225-226.

147 Satchithananda DK, Walsh J, Schofield PM: Bacterial endocarditis following repeated tattooing. Heart 2001;85:11-12.

148 Tse D, Khan S, Clarke S: Bacterial endocarditis complicating body art. Int J Cardiol 2009; 133: e28-e29.

149 Korman TM, Grayson ML, Turnidge JD: Polymicrobial septicaemia with Pseudomonas aeruginosa and Streptococcus pyogenes following traditional tattooing. J Infect 1997; 35:203.

150 Colebunders R, Depraetere K, Verstraeten T, Lambert J, Hauben E, Van Marck E, Maurer T, Banuls AL, Dujardin JC: Unusual cutaneous lesions in two patients with visceral leishmaniasis and HIV infection. J Am Acad Dermatol 1999;41:847-850.

151 Paradisi A, Capizzi R, De Simone C, Fossati B, Proietti I, Amerio PL: Malignant melanoma in a tattoo: case report and review of the literature. Melanoma Res 2006; 16:375-376.

152 Stinco G, De Francesco V, Frattasio A, Quinkenstein E, Patrone P: Malignant melanoma in a tattoo. Dermatology 2003;206: 345-346.

153 Soroush V, Gurevitch AW, Peng SK: Malignant melanoma in a tattoo: case report and review of the literature. Cutis 1997;59:111112.

154 Kircik L, Armus S, van den Broek H: Malignant melanoma in a tattoo. Int J Dermatol 1993;32:297-298

155 Singh RS, Hafeez Diwan A, Prieto VG: Potential diagnostic pitfalls in melanoma arising in a cutaneous tattoo. Histopathology 2007;51:283-285.

156 Khan IU, Moiemen NS, Firth J, Frame JD: Malignant melanoma disguised by a tattoo. Br J Plast Surg 1999;52:598.
157 Shariff Z, Tehrani H, Jagadeesan J, Hardwicke J: Artwork: to be studied. Dermatol Online J 2006; 12:21.

158 Varga E, Korom I, Varga J, Kohán J, Kemény L, Oláh J: Melanoma and melanocytic nevi in decorative tattoos: three case reports. J Cutan Pathol 2011;38:994-998.

159 Doumat F, Kaise W, Barbaud A, Schmutz JL: Basal cell carcinoma in a tattoo. Dermatology 2004;208: 181-182.

160 Birnie AJ, Kulkarni K, Varma S: Basal cell carcinoma arising in a tattoo. Clin Exp Dermatol 2006;31:820-821.

161 Kluger N, Phan A, Debarbieux S, Balme B, Thomas L: Skin cancers arising in tattoos: coincidental or not? Dermatology 2008;217: 219-221.

162 Omidian M, Emad-Mostofi N: Basal cell carcinoma arising from traditional tattoo. Arch Iran Med 2009; 12: 198.

163 Ortiz A, Yamauchi PS: Rapidly growing squamous cell carcinoma from permanent makeup tattoo. J Am Acad Dermatol 2009; 60: 1073-1074.

164 Pitarch G, Martinez-Menchon T, MartinezAparicio A, Sanchez-Carazo JL, Munoz D, Fortea JM: Squamous cell carcinoma over tattoos. J Am Acad Dermatol 2007;56:10721073.

165 Goldenberg G, Patel S, Patel MJ, Williford P, Sangueza O: Eruptive squamous cell carcinomas, keratoacanthoma type, arising in a multicolor tattoo. J Cutan Pathol 2008; 35 : 62-64.

166 Kluger N, Minier-Thoumin C, Plantier F: Keratoacanthoma occurring within the red dye of a tattoo. J Cutan Pathol 2008;35:504507.

167 Chorny JA, Stephens FV, Cohen JL: Eruptive keratoacanthomas in a new tattoo. Arch Dermatol 2007; 143:1457-1458.

168 Fraga GR, Prossick TA: Tattoo-associated keratoacanthomas: a series of 8 patients with 11 keratoacanthomas. J Cutan Pathol 2010; 37:85-90.

169 Baker PA, O’Dowd GJ, Khan IU: Dermatofibrosarcoma protuberans arising in a decorative tattoo. Sarcoma 2005;9:37-41.

170 West CC, Morritt AN, Pedelty L, Lam DG: Cutaneous leiomyosarcoma arising in a tattoo - 'a tumour with no humour'. J Plast Reconstr Aesthet Surg 2009;62:e79-e80.

171 Persechino S, Caperchi C, Bartolazzi A: Melanoma mimicry on a tattoo: an autograft hypothesis. J Am Acad Dermatol 2007; 57: S122-S123.

172 Reddy KK, Hanke CW, Tierney EP: Malignancy arising within cutaneous tattoos: case of dermatofibrosarcoma protuberans and review of literature. J Drugs Dermatol 2011; 10:837-842. 